\title{
An assessment of wind energy resource in north central Nigeria, Plateau
}

\author{
A. Ahmed ${ }^{1}$, A. El-Suleiman ${ }^{2}$, A. Nasir ${ }^{3}$ \\ ${ }^{1}$ Department of Mechanical Engineering, Kano University of Science and Technology, Wudil, Nigeria \\ ${ }^{2}$ Department of Mechanical Engineering Technology, Federal Polytechnic Nasarawa, Nigeria \\ ${ }^{3}$ Department of Mechanical Engineering, Federal University of Technology Minna, Nigeria
}

Email address:

abdula2k2@yahoo.com(A. Ahmed), a.elsuleiman@gmail.com(A. El-Suleiman), nasrabdulk@yahoo.com(A. Nasir)

To cite this article:

A. Ahmed, A. El-Suleiman, A. Nasir. An Assessment of Wind Energy Resource in North Central Nigeria, Plateau. Science Journal of Energy Engineering. Vol. 1, No. 3, 2013, pp. 13-17. doi: 10.11648/j.sjee.20130103.11

\begin{abstract}
In this paper, the wind data for Plateau North Central Nigeria was collected at $10 \mathrm{~m}$ height for seven years (2000-2006) at meteorological station Abuja. The assessment for the site is gaining importance for the installation of an appropriate wind turbine at the location. The highest wind speed for this location was found to be $15.4 \mathrm{~m} / \mathrm{s}$ in January and the lowest wind speed is $8.7 \mathrm{~m} / \mathrm{s}$ in August within the period of years considered. The study was carried out using the Weibull parameters scale $(c \mathrm{~m} / \mathrm{s})$ and shape $(k)$ factors and result obtained for these parameters have an average value of $10.76 \mathrm{~m} / \mathrm{s}$ and 7.47 respectively. These values indicate that the wind would be useful for power generation over a longer period. The power density for this location varies between 368 and $1056 \mathrm{~W} / \mathrm{m}^{2}$, this also shows that Plateau is a good location for wind power generation.
\end{abstract}

Key words: Wind Speed, Wind Power, Plateau, Weibull Distribution, Shape and Scale Factors

\section{Introduction}

Wind energy is one of the most significant and rapidly developing renewable energy sources all over the world. Recent technological developments, fossil fuel usage, environmental effects and continuous increase in the conventional energy resources has rendered wind energy costs to economically attractive levels and consequently, wind energy farms are being considered as alternative energy source in many enterprises [1]. The beneficial characteristics of wind power include clean and inexhaustible fuel, local economic development, modular and scalable technology, reduces on import fuels and energy price stability. The problem being faced is that some of the wind turbines have failed completely or performed below expectation especially in developing countries because the installed wind turbine system do not match up with the site the machines is been installed [2].

The wind speed distribution is of great importance for the assessment of wind energy potential and the performance of wind energy conversion system. Various parameters of the wind are to be known, including the mean wind speed, directional data, seasonal and annual variation with heights. These parameters are highly site specific and can only be determined with sufficient accuracy by measurements at a particular site over a sufficient long period. The Weibull distribution has been extensively used to describe the frequency distribution of wind speeds for the purpose of evaluating the energy [2].

Durisic [3] assessed wind energy resource in the south Banat region, Serbia. His assessment revealed that south Banat possesses good wind energy potential and have a promising region for development of the project for wind farms.

Alsaad [4] worked on wind energy potential in selected areas in Jordan. The study reveals that the total rated wind power that can be generated from the four selected wind farms is $136 \mathrm{MW}$ while the expected total energy that can be produced from the four selected wind farms is $18.9 * 10^{3}$ GWh.

Ojosu [5] presented a statistical analysis of wind energy potential for power generation in Nigeria, 15 years (1968-1983) monthly average wind speed data was used for six sites at four distinctive regions in Nigeria using Weibull distribution. The analysis shows that wind turbine can generate up to $97 \mathrm{MWh} /$ year.

In this study, an assessment of wind energy in Plateau, north central Nigeria was analyzed using wind speed data collected at $10 \mathrm{~m}$ height during the period $(2000-2006)$ in 
meteorological station Abuja, Nigeria.

\section{Characteristics of the Wind}

The present study is based on a data source measured at a height of $10 \mathrm{~m}$ above the ground level, the wind speed data were collected during the period (2000-2006) for this location and was obtained from the meteorological station Abuja, Nigeria. Plateau is a state in the north central Nigeria with latitude $9056 \mathrm{~N}$ and longitude $8 \mathrm{o} 53 \mathrm{E}$, it covers $8000 \mathrm{~km} 2$ and have temperature ranging from 210 to $25 \mathrm{o}$.

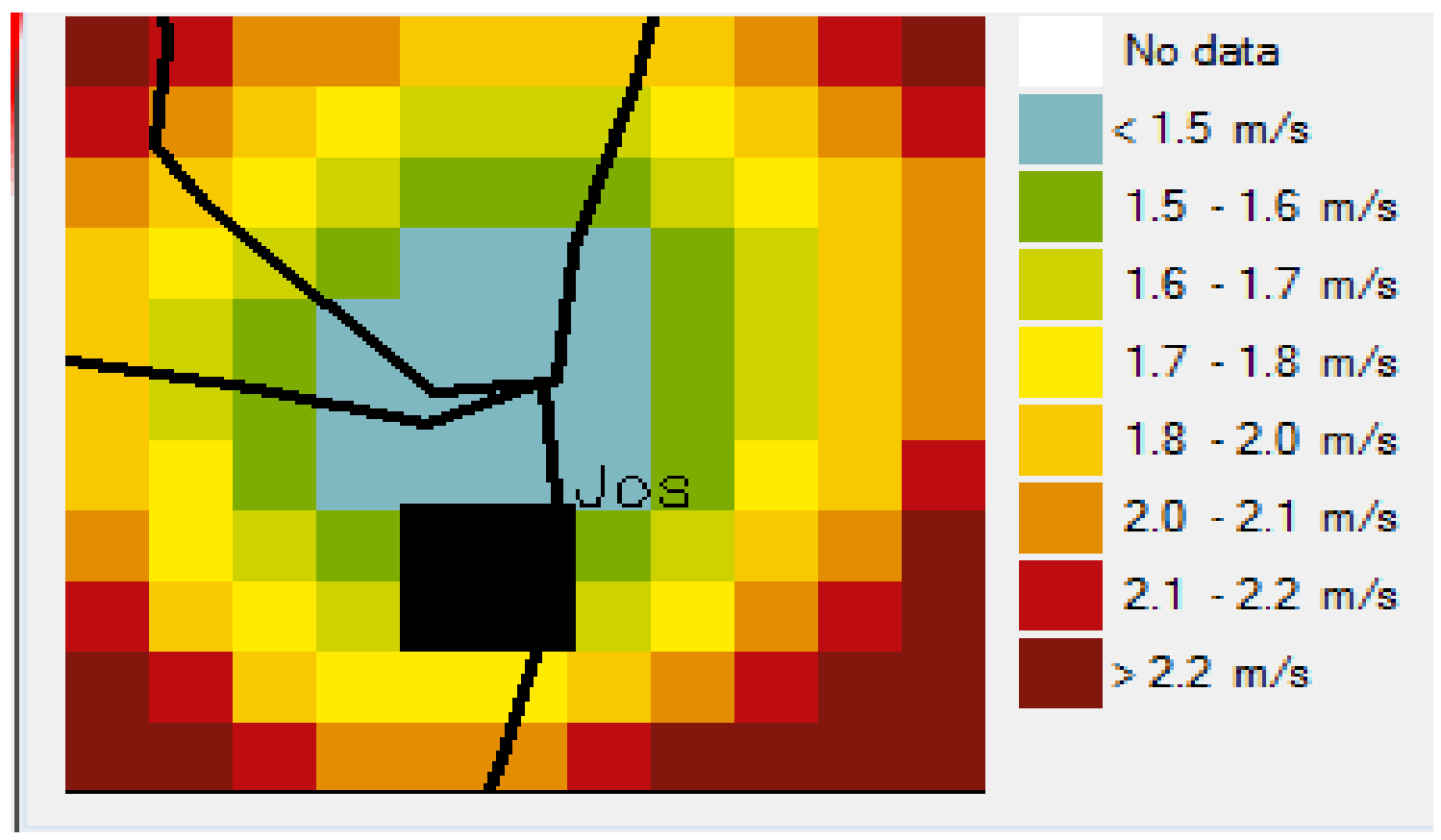

Fig 1. Map of various location of wind speed in Plateau north central Nigeria

Table 1. Monthly average wind speeds between the years 2000 and 2006 in Plateau, Nigeria

\begin{tabular}{lccccccc}
\hline Month & Year & & & & & & \\
\hline & 2000 & 2001 & 2002 & 2003 & 2004 & 2005 & 2006 \\
January & 11.4 & 11.7 & 15.4 & 10.6 & 11.5 & 14.4 & 14.2 \\
February & 13.5 & 12.0 & 12.1 & 12 & 13.4 & 13.3 & 13.7 \\
March & 13.7 & 12.3 & 12.1 & 11.6 & 12.7 & 11.2 & 9.1 \\
April & 12.8 & 11.9 & 12 & 11.5 & 13.1 & 12.4 & 9.8 \\
May & 11.6 & 11.5 & 12.7 & 11.4 & 12.3 & 11.9 & 9.7 \\
June & 12.6 & 11.8 & 11.8 & 10.5 & 11.3 & 11.3 & 10.2 \\
July & 10.8 & 11.6 & 10.6 & 10.8 & 9.8 & 11.3 & 9.9 \\
August & 9.6 & 11.2 & 10.7 & 10.9 & 11.8 & 11.2 & 8.7 \\
September & 9.7 & 9.4 & 9.7 & 9.7 & 8.9 & 9.7 & 9.2 \\
October & 10.6 & 10.8 & 10 & 9.7 & 10.6 & 10.5 & 9.9 \\
November & 11.2 & 12.2 & 11.1 & 11.3 & 11.7 & 11.9 & 10.9 \\
December & 11.4 & 13.1 & 13.2 & 12.8 & 11.9 & 12.4 & 9.3 \\
Average & $\mathbf{1 1 . 5 8}$ & $\mathbf{1 1 . 6 3}$ & $\mathbf{1 1 . 7 8}$ & $\mathbf{1 1 . 0 7}$ & $\mathbf{1 1 . 5 8}$ & $\mathbf{1 1 . 7 9}$ & $\mathbf{1 0 . 3 8}$ \\
\hline
\end{tabular}

Figure 1 shows wind map for the chosen region, Plateau has an elevation of 1217 meters and is composed mainly of granite and covered with grasslands. Tin is mined and processed, also farming and grazing activities are done in Plateau.

The monthly mean wind speed variation during the period 2000-2006 at Plateau north central Nigeria is presented in Table 1.

\subsection{Weibull Distributional Parameters of Wind Speed}

The knowledge of wind speed distribution is a very important factor in evaluating the wind potential in an area. In the wind energy analysis, it is necessary to have only few key parameters that explain the behaviour of a wide range of wind speed data. The simplest and most practical method for the procedure is to use a distribution function. The Weibull distribution which is a two parameter distribution and can be expressed as [11];

$$
\begin{aligned}
& f_{w}(v)=\left(\frac{k}{c}\right)\left(\frac{v}{c}\right)^{k-1} \exp \left[-\left(\frac{v}{c}\right)^{k}\right] \\
& F_{W}(V)=1-\exp \left[-\left(\frac{v}{c}\right)^{k}\right]
\end{aligned}
$$

Where; $f_{w}(v)=$ Weibull Probability density function $k=$ Shape factor (dimensionless)

$c=$ Scale factor $(\mathrm{m} / \mathrm{s})$

$v=$ wind speed $(\mathrm{m} / \mathrm{s})$

In order to estimate Weibull parameters ( $k$ and $c$ ), equations (3) and (4) are used.

The shape factor and scale factor of the Weibull distribution are given as: 


$$
\begin{gathered}
k=\left(\frac{\sigma}{v_{m}}\right)^{-1.086} \\
c=v_{m}\left(\frac{k^{2.6674}}{0.184+\left(0.816 k^{2.73859}\right)}\right) \\
\sigma=\left[\frac{1}{N-1} \sum_{i=1}^{N}\left(v_{i}-v_{m}\right)^{2}\right]^{1 / 2}
\end{gathered}
$$

where

$v_{m}=$ Mean wind speed class intervals $(\mathrm{m} / \mathrm{s})$

$v_{i}=$ observed wind speed $(\mathrm{m} / \mathrm{s})$

$\mathrm{N}=$ Number of months in the period of time considered.

$\sigma=$ standard deviation

\section{Analysis of Wind Speed Data}

\subsection{Wind Speed Probability Distributions}

Table 2. Arrangement of measured monthly time series data in frequency distribution format.

\begin{tabular}{cccccc}
\hline $\boldsymbol{j}$ & $\boldsymbol{V}_{\boldsymbol{j}}$ & $\boldsymbol{V}_{\boldsymbol{m} \boldsymbol{j}}$ & $\boldsymbol{f} \boldsymbol{j}$ & $f v j$ & $f \boldsymbol{f}(\boldsymbol{v j})$ \\
\hline 1 & $0-0.9$ & 0.45 & 0 & 0.000 & $1.92479 \mathrm{E}-08$ \\
2 & $1-1.9$ & 1.45 & 0 & 0.000 & $7.60425 \mathrm{E}-06$ \\
3 & $2-2.9$ & 2.45 & 0 & 0.000 & 0.000110939 \\
4 & $3-3.9$ & 3.45 & 0 & 0.000 & 0.000637626 \\
5 & $4-4.9$ & 4.45 & 0 & 0.000 & 0.00238006 \\
6 & $5-5.9$ & 5.45 & 0 & 0.000 & 0.006559892 \\
7 & $6-6.9$ & 6.45 & 1 & 0.059 & 0.015351885 \\
8 & $7-7.9$ & 7.45 & 0 & 0.000 & 0.031327342 \\
9 & $8-8.9$ & 8.45 & 3 & 0.176 & 0.056942856 \\
10 & $9-9.9$ & 9.45 & 2 & 0.118 & 0.092707778 \\
11 & $10-10.9$ & 10.45 & 1 & 0.059 & 0.134180501 \\
12 & $11-11.9$ & 11.45 & 1 & 0.059 & 0.169219402 \\
13 & $12-12.9$ & 12.45 & 4 & 0.235 & 0.179868383 \\
14 & $13-13.9$ & 13.45 & 5 & 0.294 & 0.153606809 \\
15 & $14-14.9$ & 14.45 & 1 & 0.059 & 0.098817284 \\
\hline
\end{tabular}

The wind speed probability distribution is in time series format usually arranged in the frequency distribution for- mat. The available time series data were translated into frequency distribution format, which is illustrated in table 2 below. The wind speed is grouped into classes (bins) as given in the second column of table 2. The mean wind speeds are calculated for each speed intervals (third column). The fourth column gives the frequency of occurrence of each speed class. The probability density distribution is presented in fifth column.

\subsection{Wind Power Density}

The knowledge of the wind characteristics and evaluation of the power in wind is very important for an assessment of wind power project. The wind power depends on the air density, the cube of the wind speed and the wind speed frequency distribution. Therefore, this parameter is generally considered a better indicator of the wind resource than wind speed. The mean wind power density is proportional to the mean cube of the wind speed, $v^{3}$ and can be estimated by using the following equation [15];

$$
P=\frac{1}{2} \rho v^{3}
$$

where, $\quad \boldsymbol{\theta}$ is air density, usually taken as $1.225 \mathrm{~kg} / \mathrm{m}^{3}$.

\subsection{Extrapolation of Wind Speed at Different Hub Height}

The increase in wind speed with respect to height can be calculate using equation (7) below. The available wind speed data are measured at height different from the hub height [12]. In this work, the power law is used for the extrapolation of wind speed at different hub height.

$$
\frac{v}{v_{o}}=\left(\frac{h}{h_{o}}\right)^{\alpha}
$$

where;

$v=$ wind speed at required height $\mathrm{h}$

$v_{o}=$ wind speed measured at reference height $\mathrm{h}_{\mathrm{o}}$

$\alpha=$ surface roughness coefficient, usually taken as 0.143 .

\section{Results and Discussion}

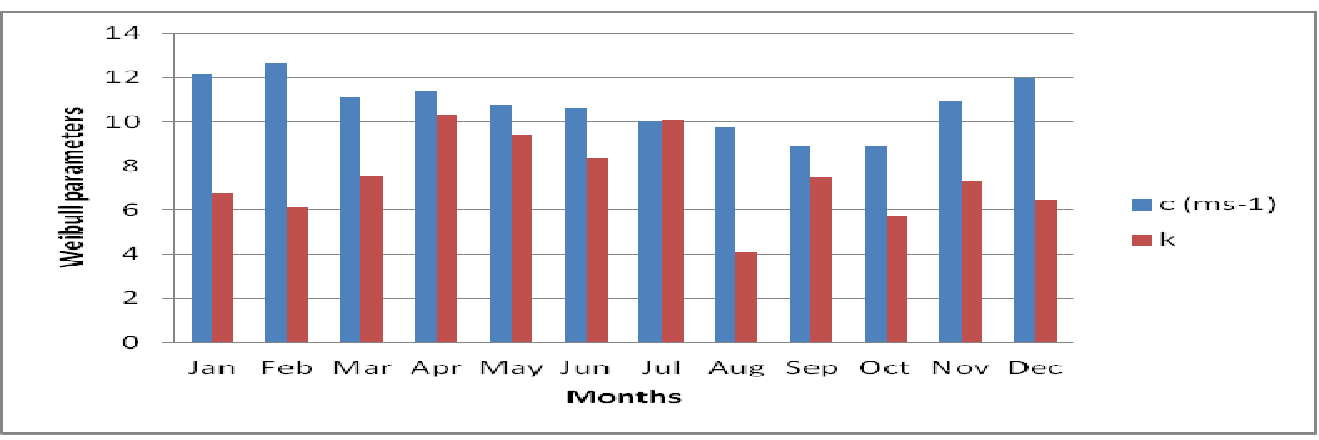

Figure 2. Weibull parameters for Plateau North Central Nigeria. 


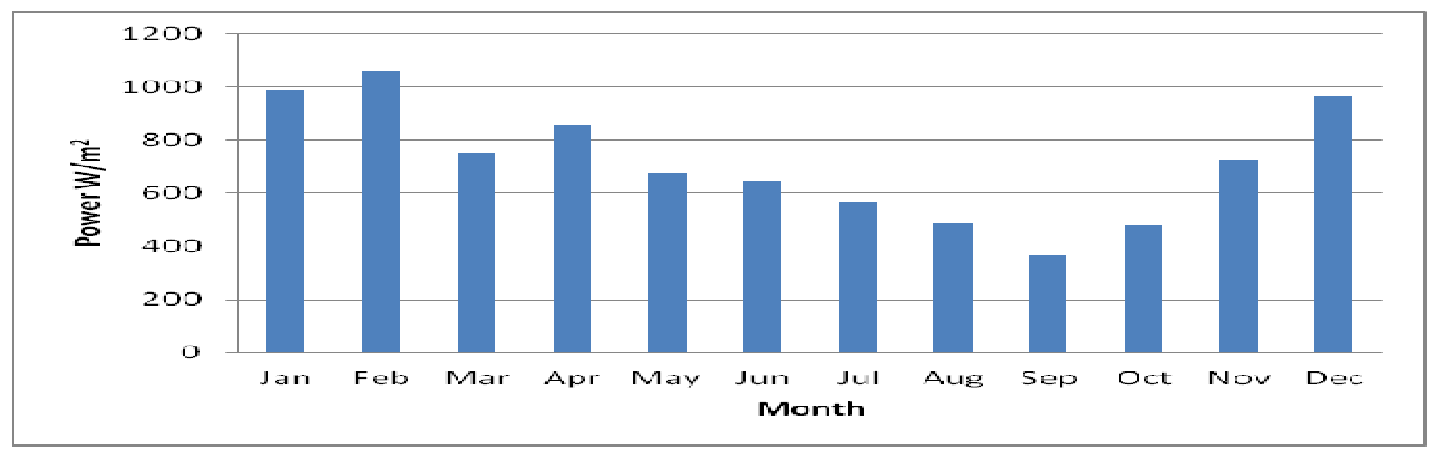

Figure 3. Power density for Plateau North Central Nigeria

Figure 2 shows monthly variation of Weibull parameters for Plateau during the period $(2000-2006)$. It can be observed from the graph that Weibull shape parameter $k$ varies between $5.74-10.32$, while scale parameter $c$ varies between $8.86-12.63 \mathrm{~m} / \mathrm{s}$.

Figure 3 shows the average power density in months for Plateau, it can be seen that the lowest power density is
$368 \mathrm{~W} / \mathrm{m}^{2}$ in month of September and the highest power density is $1056 \mathrm{~W} / \mathrm{m}^{2}$ in month of February. From the range of the wind power density, Plateau in North Central Nigeria has enough wind energy for electricity generation.

Figure 4 shows Weibull probability density function for Plateau. As seen in the graph the dry and wet season have similar trend in wind speed pattern.

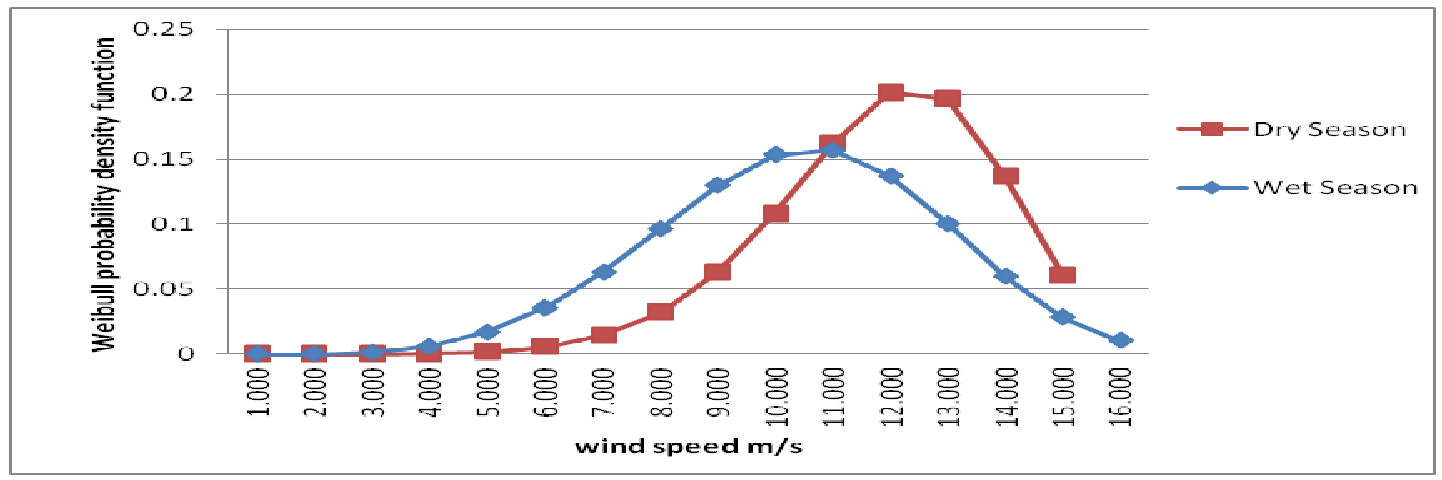

Figure 4. Weibull probability density function for Plateau North Central Nigeria

\section{Conclusion}

In this study, the monthly wind speed and wind power density for the period of $2000-2006$ in Plateau North Central Nigeria was analyzed using the Weibull distribution model. The following conclusion can be drawn from the results of the study:

- The highest monthly mean wind speed is determined as $15.4 \mathrm{~m} / \mathrm{s}$ in January 2002, while the lowest mean wind speed $8.7 \mathrm{~m} / \mathrm{s}$ in August 2006. Annual mean wind speed for a seven year period is obtained as $11.4 \mathrm{~m} / \mathrm{s}$.

- $\quad$ The lowest wind power density occurred in September with value $368 \mathrm{~W} / \mathrm{m} 2$ and highest value of $1056 \mathrm{~W} / \mathrm{m} 2$ in February.

- The average value for Weibull shape parameters $\mathrm{k}$ and c were found as 7.47 and $10.76 \mathrm{~m} / \mathrm{s}$ for the period 2000 - 2006, respectively.

- $\quad$ Plateau in the North Central Nigeria have potential for wind energy exploitation.

Plateau North Central Nigeria is a perspective region in building a wind turbine. The basic characteristic favouring this region in terms of possible use of wind power are: good wind speed, good wind potential, good climatic con- ditions, availability of land for possible wind turbine installation.

\section{References}

[1] Akinpar EK, Akinpar S. Determination of the wind energy potential for Maden, Turkey. Energy Conversion and Management 2004; 45(18 - 19):2901 - 2914.

[2] Ahmed Shata AS, Hanitsch R. Evaluation of wind energy potential and electricity generation on the coast of Mediterranean Sea Egypt. Renewable Energy 2006; 31: 1183-202.

[3] Durisic Z, Mikulovic J. Assessment of the wind energy resource in the south Banat region Serbia. Renewable and Sustainable Energy Reviews 2012; 16: 3014 - 3023.

[4] Alsaad M.A. Wind energy potential in selected areas of Jordan. Energy Conversion and Management 2013; 65: 704 -708 .

[5] Ojosu JO, Salawu RI: A statistical analysis of wind energy potential for power generation in Nigeria. Solar and Wind Technology 1990; 7: 155 - 167.

[6] Celik AN. On the distributional parameters used in assessment of the suitability of wind speed probability density 
functions. Energy Conversion and Management 2004; $45: 1735-1747$.

[7] Celik AN. A statistical analysis of wind power density based on the Weibull and Rayleigh Models at the southern region of Turkey. Renewable Energy 2004; 29:593 - 604.

[8] Celik AN. Assessing the suitability of wind speed probability distribution functions based on the wind power density. Renewable Energy 2003; 28: 1563 -1574.

[9] Salem AL. Characteristics of surface wind speed and direction over Egypt .Solar Energy F or Sustainable Development 2001;44: $491-499$.

[10] Ulgen K, Hepbasli A. Determination of Weibull parameter for wind energy analysis of Izmir, Turkey. International Journal of Energy Research 2002; 26:495 - 506.
[11] Ahmed SA. Investigation of wind characteristics and wind energy potential at Ras Ghareb, Egypt. Renewable and Sustainable Energy Reviews 2011; 15:2750-5.

[12] Stevens MJM, Smulders PT. The estimation of the parameters of the Weibull wind speed distribution for wind energy utilization purposes. Wind Engineering 1979; 3(2): 132-84.

[13] Watts D, Jara D. Statistical analysis of wind energy in Chile. Renewable Energy 2011; 36: 1603-13.

[14] Anagreh Y. Ahmad B. Renewable energy potential assessment in Jordan. Renewable and Sustainable Energy Review 2011; 15: 2232-9. 